\title{
KONSEP ADAPTASI BUDAYA PARTUTURON TERHADAP FILM HARANI ADAT
}

\author{
Muhammad Ali Mursid Alfathoni \\ Prodi Televisi dan Film \\ Fakultas Seni dan Desain Universitas Potensi Utama \\ Mhd.ali8mursid@gmail.com
}

\begin{abstract}
ABSTRAK
Penelitian ini bertujuan untuk mendeskripsikan proses adaptasi realitas budaya Partuturon yang terdapat dalam film Harani Adat. Film Harani Adat merupakan sebuah film indie yang disutradarai oleh Sulaiman S dan di produksi pada tahun 2016 oleh RMP. Production. Proses adaptasi budaya Partuturon terhadap film Harani Adat Sutradara Sulaiman S diawali dengan bentuk interaksi antar sesama yang menggunakan bentuk-bentuk budaya Partuturon. Pada saat proses adapatasi dalam film Harani Adat juga terjadi aspek penambahan maupun perubahan dari segi alur cerita. Proses tersebut bertujuan untuk menambah efek dramatik serta menggiring konflik agar mencapai klimaks. Peneliti menggunakan pendekatan kualitatif untuk mendeskripsi setiap proses adaptasi budaya Partuturon yang terjadi di dalam film Harani Adat. Selain itu, peneliti juga menggunakan teori Linda Hutcheon agar proses deskripsi bentuk-bentuk adaptasi budaya Partuturon dapat diuraikan dengan sebaik mungkin.dalam realitas budaya Partuturon terkandung makna yang bisa menjadi pedoman setiap individu dalam bermasyarakat. Pedoman tersebut menjadi paduan agar tidak salah langkah pada saat berinteraksi sosial dan mengambil tindakan.
\end{abstract}

Kata kunci: Adapatasi, Film Harani Adat, Partuturon.

\section{ABSTRACT}

This study aims to describe the process of adaptation to the reality of Partuturon culture contained in the film Harani Adat. The film Harani Adat is an indie film directed by Sulaiman $S$ and produced in 2016 by RMP. Production. The adaptation process of Partuturon culture to the film Harani Adat Director Sulaiman $S$ begins with a form of interaction between people who use the forms of Partuturon culture. During the adaptation process in the film Harani Adat there were also aspects of addition and change in terms of the storyline. The process aims to add dramatic effects and lead conflict to climax. The researcher used a qualitative approach to describe each process of Partuturon cultural adaptation that occurred in the film Harani Adat. In addition, the researcher also used Linda Hutcheon theory so that the description process of the forms of adaptation of Partuturon culture could be described as well as possible. In reality the culture of Partuturon contained meaning that could guide each individual in society. The guideline becomes an alloy so that there is no wrong step when interacting socially and taking action.

Keywords: Adaptation, Film Harani Adat, Partuturon.

\section{PENDAHULUAN}

Indonesia merupakan sebuah Negara yang memiliki keberagaman suku bangsa, etnis, bahasa, kepercayaan dan adat istiadat. Salah satu bentuk keberagaman tersebut ditandai dengan adanya sebuah suku yang mendiami pulau Sumatera, yaitu suku Batak. Memiliki keunikan kebudayaan yang menjadi ciri chas tersendiri dari suku lainnya.. Keunikan tersebut ini tercermin dari kebudayaan yang dimiliki oleh suku Batak, baik dari aspek keyakinan beragama agama, mata pencarian, kesenian, adat-istiadat dan 
sebagainya. Secara geografis suku Batak Angkola-Mandailing berasal dari wilayah Kabupaten Tapanuli Selatan (Tapsel), Kota Padang Sidempuan , Kabupaten Padang Lawas, Kabupaten Padang Lawas Utara, dan Kabupaten Mandailing Natal (Madina) yang terletak di antara Rao (Provinsi Sumatra Barat) dan Pahae (Tapanuli Utara), Samudra Hindia, dan Rokan Hulu (Riau). (Rendra, 2014: 143-144). Dalam kehidupan bermasyarakat Batak Angkola-Mandailing mengenal adanya budaya Partuturon. Partuturon merupakan istilah kekerabatan yang memuat nilai-nilai luhur adab pergaulan orang per-orang dan kelompok per kelompok dalam masyarakat (Husniah Pulungan, 2015: 309). Partuturon dalam realitas budaya Batak Angkoa-Mandailing merupakan istilah untuk menentukan hubungan berdasarkan sistem adat. Sebutan tersebut berfungsi untuk menentukan posisi setiap orang dalam sistem kekerabatan Dalihan Na Tolu. Dalam sistem aturan adat Dalihan Na Tolu masyarakat Batak Angkola-Mandailing mengenal istilah kahanggi, anak boru dan mora yang berfungsi untuk menyelesaikan permasalahan yang menyangkut aturan adat istiadat yang ada dalam realitas masyarakat Batak AngkolaMandailing.

Budaya Partuturon merupakan salah satu tanda bahwa Indonesia memiliki keberagaman budaya yang menjadi ciri khas dan penanda sutu suku. Realitas budaya Partuturon tersebut diangkat oleh seorang sutradara menjadi media film yang bertujuan untuk meperkenalkan kepada khayalayak akan pentingnya setiap generasi memahami dan mengetahui realitas budaya yang ada di dalam sukunya. Film merupakan sebuah karya seni yang diproduksi secara kreatif dan mengandung suatu nilai positif maupun negatif, sehingga mengandung suatu makna yang sempurna (Rahmah, 2014: 23). Menurut Pratista (2008: 1-2) bahwa film dibagi atas unsur pembentukannya yakni, unsur naratif dan unsur sinematik. Unsur tersebut saling berkesinambungan dalam membentuk sebuah film yang mejalinkan peristiwa yang memiliki maksud dan tujuan (Pratista, 2008: 1-2). Film yang memiliki kemampuan dalam menyajikan pesan yang berbentuk media audio visual yang memadukan unsur naratif dan sinematik tentu memiliki tujuan agar alur cerita yang ada di dalam film bisa membawa dampak yang negatif terhadap penonton. Saat ini, berbagai judul film banyak yang diadaptasi dari realitas budaya yang mulai dilupakan oleh pemilik kebudayaan tersebut. Sehingga dengan adanya media film realitas budaya yang ada serta nilai-nilai yang terkandung di dalamnya bisa terekpos kembali di tengah perkembangan teknologi informasi pada saat sekarang ini seperti halnya film Harani Adat.

Adaptasi merupakan proses atau cara menyesuaikan terhadap lingkungan, kondisi atau bentuk yang baru (Hadipratama, 2017: 10). Proses adaptasi merupakan salah satu bentuk kreatif yang dilakukan oleh seorang sutrdara dalam mengangkat realitas fenomena budaya ke dalam sebuah media seperti film. Adaptasi tentang realitas budaya Partuturon dalam film Harani Adat tentu mengalami serangkaian perubahan bahkan mengalami penambahan baik dari aspek alur cerita. Proses perubahan dan penambahan tentu memiliki tujuan untuk menambah efek dramatis dalam penyampaian alur cerita dalam film Harani Adat. Proses adaptasi yang dilakukan oleh sutrdara film Harani Adat merupakan bentuk langkah yang sangat efektif dalam memperkenalkan kembali nilai-nilai budaya yang ada dalam realitas budaya Partuturon dalam keyakinan masyarakat Batak AngkolaMandailing. Alur cerita tentang realitas budaya Partuturon dalam film Harani Adat merupakan rangkaian peristiwa-peristiwa yang senantiasa dijalin dengan sedemikian rupa yang berfungsi untuk mengerakkan jalan cerita baik melalui proses perumitan sampai ke proses klimaks (Andi, 2015: 238). Peneliti menggunakan pendekatan deskripsi kualitatif dengan memadukan teori Adaptasi Linda Hutcheon untuk mendeskripsi proses adaptasi realitas budaya Partuturon yang ada dalam film Harani Adat Sutradara Sulaiman S. 


\section{II.STUDI LITERATUR}

Hasil penelitian Dwi Putri Nugrahaning Widhi yang berjudul "Realitas Ludic Dalam Film Dokumenter (Studi Kasus Film Di Balik Frekuensi Karya Ucu Agustin)" tahun 2015 yang berbentuk Tesis. Menurut hasil penelitian Dwi Putri Nugrahaning Widhi Film Di Balik Frekuensi terdapat serangkaian realitas yang diciptakan oleh pembuat film melalui unsur audio dan visual, di antaranya narasi, ilustrasi musik, sound effect, teks, gambar, slow motion, fast motion dan sebagainya. Melalui rangkaian realitas yang ada di dalam film tersebut, tanpa disadari bahwa di dalam film dokumenter Di Balik Frekuensi terdapat unsur ludic. Rangkaian realitas dalam film tersebut tidak lepas dari ideologi dari sang sutradara yang berkaitan dengan rangkaian makna pesan yang disampaikan secara persuasif maupun tendensius. Dwi Putri Nugrahaning Widhi dalam penelitiannya untuk mendiskripsikan realitas yang ada dalam film Dokumenter Di Balik Frekuensi Karya Ucu Agustin menggunakan pendekatakan tafsir serta menerapakn teori ludic dan teori realitas.

Yang menjadi rujukan peneliti selanjutnya adalah, hasil penelitian Rangga Karina Dian Anjani yang berjudul "Adaptasi Film Winnie The Pooh Menjadi Vinni Pukh Sebagai Tinjaun Rusifikasi)" tahun 2012 yang berbentuk skripsi. Skripsi ini membahas proses pengadaptasian Winnie the Pooh menjadi Vinni Pukh dengan menggunakan tinjauan rusifikasi, serta mendeskripsikan makna dari perbedaan yang tercipta dari proses adaptasi. Dalam proses merusifikasi dalam film Vinni Pukh tentu terdapat sebuah proses penting yang mendukung jalannya alur cerita. Proses merusifikasi tersebut adalah proses adaptasi. Rangga Karina Dian Anjani menggunakan teori adaptasi dan semiotika untuk melakaukan proses deskripsi terhadap makna yang terkandung di dalam film tersebut. Rangga Karina Dian Anjani juga menggunakan metode deskriptif-analitis yang berfungsi untuk mendukung teroi yang digunakannya. Rangga Karina Dian Anjani menemukan banyak perbedaan antara Winnie the Pooh dan Vinni Pukh, namun dibalik perbedaan tersebut megandung makna yang dapat diinterpretasikan.

Selanjutnya, hasil hasil penelitian Rosliana Lubis dalam jurnal Logat yang berjudul: "Partuturon Dalam Masyarakat Angkola" tahun 2006. Rosliana Lubis menemukan bahwa dalam sistem kekerabatan serta hukum adat yang ada dalam masyarakat Batak Angkola dimulai dari satu keluarga yang berkembang menjadi beberapa bagian sehingga membentuk satu clen (marga). Masyarakat Batak Angkola mengenal ada struktur Dalihan Na Tolu yang berfugsi untuk menyelesaikan permasalahan adat istiadat. Sehingga dengan adanya struktur tersebut terciptalah sebuah budaya yang dikenal dengan budaya Partuturon. Penelitian Rosliana Lubis, menunjukkan bahwa rasa persatuan maupun kekeluargaan akan tercermin dari bentuk sopan santun serta saling menghormati yang tercetus dari interaksi sosial dengan menerapkan budaya Partuturon sesuai dengan aturan adat istiadat.

\section{PEMBAHASAN}

Film Harani Adat merupakan sebuah film Indie yang disutradarai oleh Sulaiman S yang diproduksi oleh RMP Production pada tahun 2016. Film Harani Adat bercerita seorang pemuda yang bernama Dapot yang mencoba mengadu nasib diperantauan. Namun, ketika diperantauan Dapot berkenalan dengan seorang cewek yang bernama Laila sehinga menimbulkan rasa cinta di hati keduanya. Waktu terus berlalu, hubungan Dapot dan Laila semakain dekat. Kedekatan mereka membuat mereka berdua memutuskan untuk menikah. Ketika mereka memutuskan untuk menikah namun, mendapat halangan dari pihak 
keluarga. Pihak keluarga menghalangi mereka untuk menikah karena disebabkan mereka masih terikat hubungan keluarga dalam ikatan budaya Partuturon. Proses adaptasi budaya Partuturon dalam film Harani Adat yang dilakukan oleh Sulaiman S dilakukan hanya semata-mata untuk menambah efek dramatis sehingga dalam penyampaian alur cerita tentang budaya Partuturon dapat disampaikan dengan sebaik mungkin. Hal tersebut, bertujuan untuk mempersingkat durasi film yang diproduksi. Akan tetapi, dengan keterbatasan durasi dalam film Harani Adat realitas yang menyangkut budaya Partuturon disampaikan dengan menyesuaikan dengan realitas kenyataan yang ada dalam masyarakat Batak Angkola-Mandailing.

\section{III.1. Konsep Adaptasi Realitas Budaya Partuturon Terhadap Film Harani Adat}

Adaptasi menurut Greenberg dalam buku a Theory of Adaptation karya Linda Hutcheon adalah:

Adaptation is repetition, but repetition without replication. And there are manifestly many different possible intentions behind the act of adaptation: the urge to consume and erase the memory of the adapted text or to call it into question is as likely as the desire to pay tribute by copying. Adaptations such as film remakes can even be seen as mixed in intent: "contested homage".

(“Adaptasi adalah pengulangan, tetapi pengulangan tanpa peniruan. Dan terdapat banyak kemungkinan tujuan yang berbeda dibalik suatu tindakan dari adaptasi: desakan untuk mengkonsumsi dan menghapus memori dari teks yang telah diadaptasi atau untuk membentuknya sebagai sebuah pertanyaaan bagaikan sebuah keinginan untuk membayar upeti dengan cara menyalin. Adaptasi seperti pembuatan ulang suatu film bahkan dapat dilihat sebagai percampuran tujuan: "kontes penghormatan")" (Hutcheon, 2006: 7).

Proses adaptasi budaya Partuturon dalam film Harani Adat dimulai dari bentuk interaksi yang dilakukan oleh Torkis dan Martunas. Bentuk budaya Partuturon yang digunakan oleh Torkis dan Martunas aalah kata Uda dan mang. Bentuk budaya Partutoron tersebut mencerminkan adanya hubungan kekerabatan yang terjalin antara Torkis dan Martunas dan kata-kata tersebut merupakan bentuk budaya Partuturon yang sering terucap dan terdengar ditengah masyarakat Batak Angkola-Mandailing. Kebiasaan masyarakat Batak Angkola-Mandailing pada saat berinterkasi sosial dengan sesama baik dengan sebaya maupun dengan orang tua bahkan anak-anak senantiasa mempraktek sistem kekerabatan yang tercermin dalam budaya Partuturon. Adegan tersebut terlihat seperti gambar dibawah ini: 


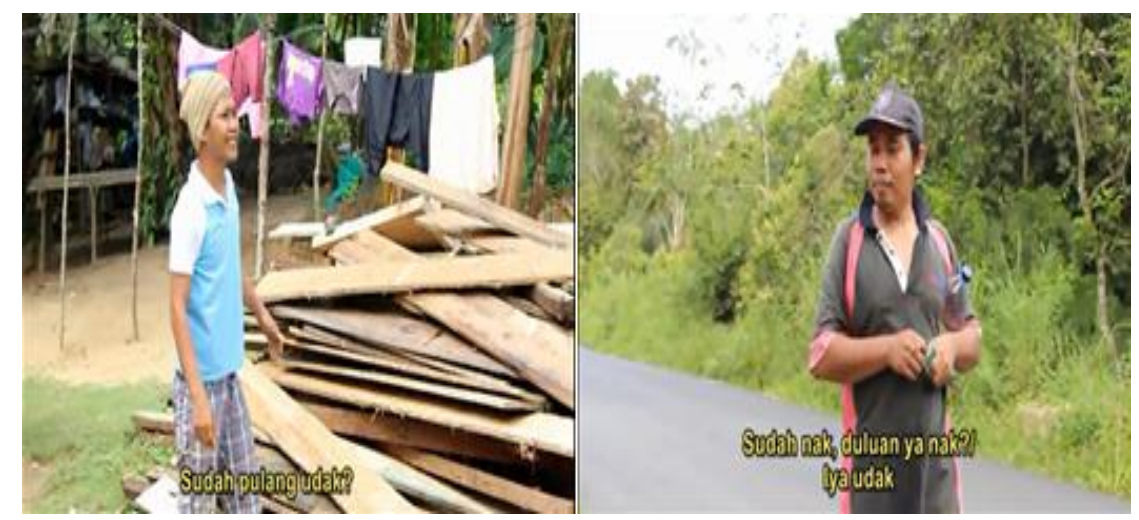

Gambar 1. Torkis dan Tunas saling bertegur sapa

(Sumber : Ali Mursid. Capture film Harani Adat, 2018)

Menurut kebiasaan masyarakat Batak Angkola-Mandailing, bentuk budaya Partuturon " $U d a$ " mencerminkan orang tersebut ada hubungan darah yang disebabkan satu keturunan ataupun marga. Dalam realitas budaya Partuturon jika seseorang dipanggil dengan Uda memiliki peran dan tanggung jawab yang sangat penting terhadap kemaslahatan keponakannya. Kewajiban tersebut dapat berupa kegiatan adat istiadat seperti, pernikahan dan sebagainya. Dalam scene 33 film Harani Adat, juga terjadi bentuk adaptasi budaya Partuturon. Pada scene 33 terlihat Dapot menggunakan budaya Partuturon "Nanguda". Dalam realitas masyarakat Batak Angkola-Mandailing seseorang yang dipanggil Nanguda merupakan istri dari paman kandung yang terjalin karena ikatan pernikahan. Adapun bentuk adegan yang terdapat dalam scenen 33 seperti terlihat pada gambar dibawah ini:

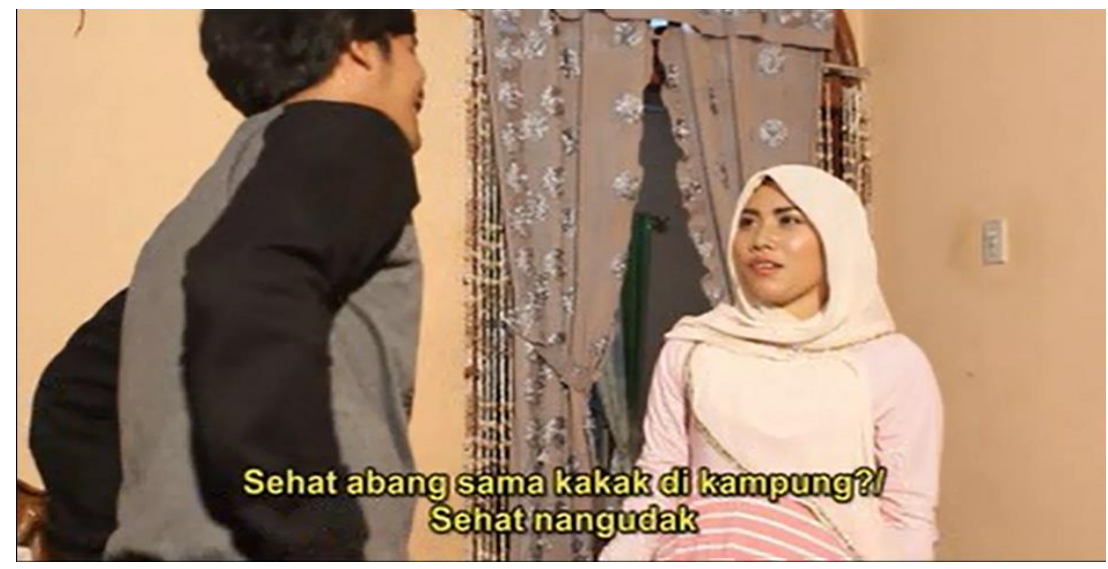

Gambar 2. Dapot menggunakan Partuturon Nanguda (Sumber : Ali Mursid. Capture film Harani Adat, 2018)

Konflik tentang realitas budaya Partuturon mulai dimunculkan dalam film Harani Adat berawal dari keinginan Dapot untuk menikah Laila. Keinginan Dapot tersebut diutarakannya kepada kedua orangnya termasuk kepada paman kandungnya. Ketika paman kandungnya mengetahui keinginan Dapot untuk menikah pamannya sangat mendukung dan setuju. Hal tersebut tercermin dalam scene 4 pada film Harani Adat sperti berikut ini: 


\section{Int. Ruang Tamu.Siang}

Tunas:

"Masalah si Dapot ta do dabole. Adong do adaboru dison nasolop dimata nia. Jadi panghobaran nialai, adong roa nialai get langka matobang, maksduna patobang adat.Imada anggi so ro u tuson mangadu.

(masalah si Dapot anak kita, ada perempuan yang dia sukai disini, jadi ada niat mereka untuk serius, maksudnya untuk menikah. Karean itulah aku datang kesini untuk mengadu."

Leman :

"Oohh. Pade mantong abang i, ima guna na adong kahanggi niba

(Oh... baguslah itu bang, itulah gunanya sanak family)" (Sumber. Film Harani

Adat. 2018).

Suasana kekeluargaan yang tentram dan penuh canda tawa. Tiba-tiba buram dan dipenuhi dengan amarah ketika paman Dapot mengetahui kalau perempuan yang ingin dinikahi keponakannya adalah Laila. Kemarahan Leman (Paman Dapot) beralasan karena Laila merupakan adik sepupu dari istrinya yang masih tergolong kerabat dekat dan memiliki hubungan darah. Kemarahan Leman terlihat pada capture film Harani Adat dibawah ini:

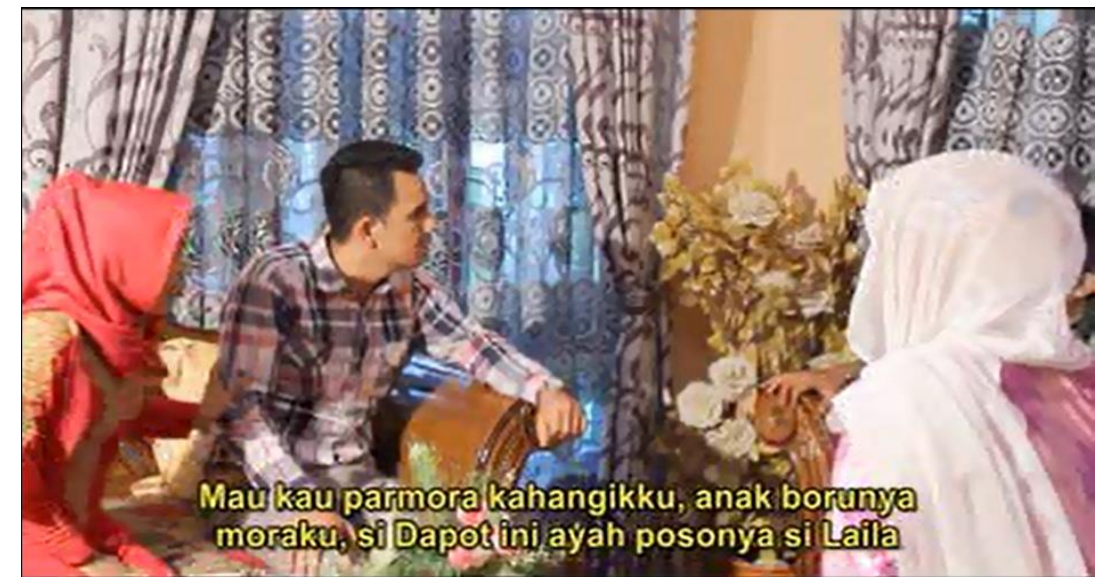

Gambar 3. Leman marah kepada Tunas

(Sumber : Ali Mursid. Capture film Harani Adat, 2018)

Dalam adegan diatas terlihat bahwa Leman lebih mengetahui sistem aturan adat berusaha menjelaskan hubungan kekerabatan yang terjalin antara dia dan keluarga Laila kepada abang kandungnya Torkis. Jika terjadi pernikahan antara Dapot Laila otomatis bisa menyebababkan tumpang tindih dalam aturan budaya Partuturon dan bisa menyebakan bergesernya nilai-nilai budaya Partuturon dalam realitas masyarakat Batak AngkolaMandailing. Dalam film Harani Adat sutradara juga melakukan proses penambahan yang mengarah ke budaya Partuturon. Penambahan hanya semata-mata berfungsi untuk menambah efek dramatis dalam penyampaian alur cerita dalam film Harani Adat. Adapun bentuk penambahan yang dilakukan oleh sutradara adalah menggunakan kata "umak si Porngas" kata tersebut berfungi untuk menunjukkan bahwa orang yang sebaya dan sudah memiliki seorang anak senantiasa dipanggil dengan menyebut nama anaknya yang bertujuan untuk memberikan pengajaran terhadap anak-anak agar terbiasa menyapa orang 
lain dengan sopan santun. Proses penambahan tersebut seperti terlihat pada capture film Harani Adat berikut ini:

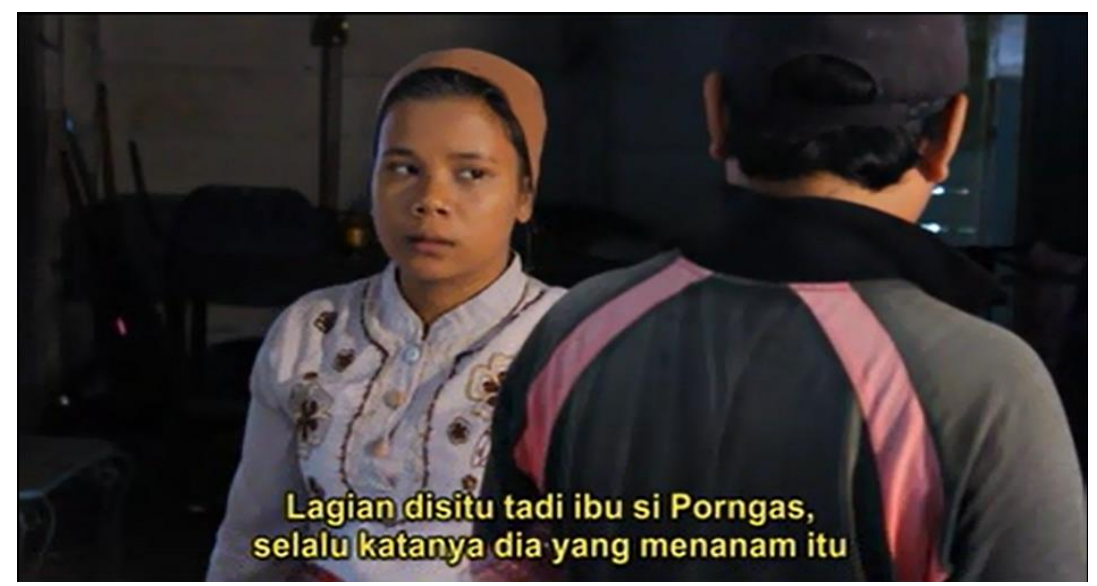

Gambar 4. Adegan penambahan budaya Partuturon (Sumber : Ali Mursid. Capture film Harani Adat, 2018)

Proses penambahan bentuk budaya Partuturon juga terjadi pada scene 15. Pada scene 15 terlihat adanya interaksi antara Leman dan Martunas melalui media telefon. Dalam interkasi tersebut mereka menggunakan istilah anak ta sebagai kata dari Dapot. Istilah anak ta menunjukkan bahwa hubungan kekerabatan yang terjalin anatar Dapot, Leman dan Martunas sangatlah dekat. Hubungan kekerabatan merek terjalin karena adanya hubungan darah dan satu nenek moyang dari turunan marga yang sama. Adapun bentuk adegan tersebut seperti terlihat pada gambar berikut ini:

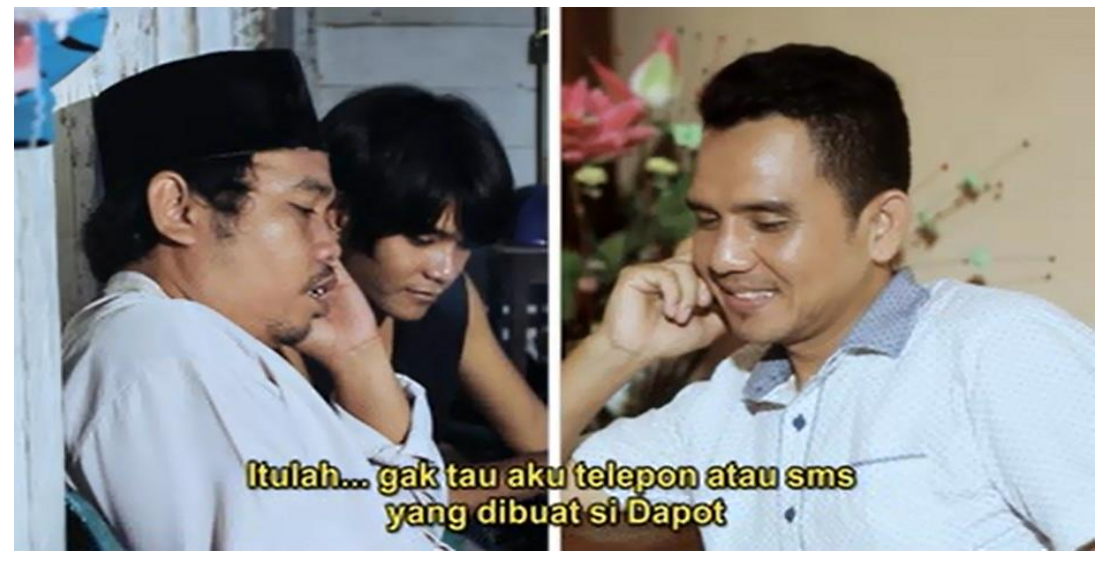

Gambar 5. Tunas dan Leman

(Sumber : Ali Mursid. Capture film Harani Adat, 2018)

Adapun aspek perubahan alur dari bentuk budaya Partuturon dalam film Harani adat terdapat dalam scene 16. Seperti terlihat pada adegan berikut ini:

16. Ext. Lapangan. malam

Dapot:

"Songonon do anggi, ngadong nasetuju di hubungan ta, tai inda bisa au malupahonko...

Onpe, anggo nabetul-betul roha ти tи аи. KAWIN LARI MAITA. 
(begini dek, adikkan tahu kalau tidak ada yang setuju dengan hubungan kita ini, tapi aku tidak bisa melupakan dirimu... sekarang kalau kamu betul-betul mencintai aku...ayo kita kawin lari” (Sumber. Film Harani Adat. 2018).

Proses perubahan alur terjadi ketika Leman yang melarang keinginan Dapot untuk menikahi Laila. Akan tetapi, Dapot yang memiliki karakter yang keras dan tidak mau mengikuti aturan adat berusaha menerobos atura-aturan yang sudah ada dalam budaya Partuturon walaupun harus melawan Leman pamannya sendiri. Konflik internal yang dialami Dapot semakin mengalami penanjakan yang sehingga membuat alur dramatikdalam film Harani Adat semakin menegangkan. Dapot berusaha dan melakukan berbagai cara agar keinginannya bisa tercapai untuk menikahi Laila. Dapot berusaha menyakinkan Laila kalau dia benar-benar mencintainya. Dapot berusaha mengajak Laila untuk kawin lari agar bisa mewujudkan bahtera rumah tangga dengan Laila tanpa ada halangan dari pamannya. Untuk menyakinkan Laila Dapot menerima persyaratan sumpah yang diajukan Laila kepadanya dengan meneteskan darah diatas sapu tangan yang bertuliskan nama masing-masing. Simbol adaptasi dengan tetesan darah diatas sapu tangan yang bertuliskan nama masing-masing mempunyai arti bahwa cinta antara Dapot dan Laia tidak akan pernah bisa dipisahkan ibarat darah yang mengalir dan menyatu dengan tubuh manusia. Adapun bentuk capture adegannya seperti terlihat pada gambar dibawah ini:

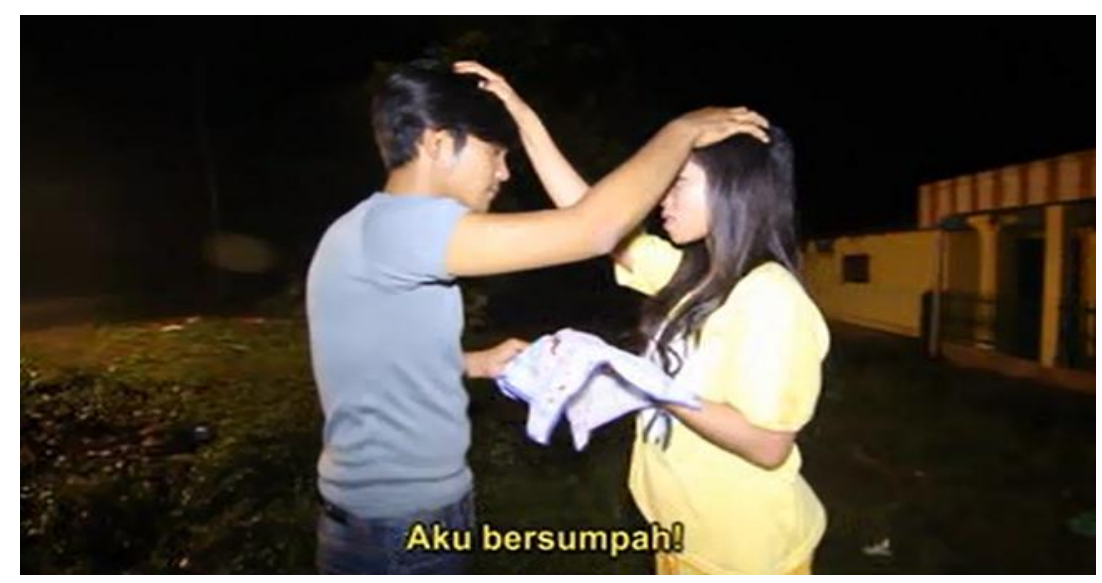

Gambar 6. Dapot dan Laila mengikat janji dengan sumpah (Sumber : Ali Mursid. Capture film Harani Adat, 2018)

Langkah yang diambil oleh Dapot mengajak Laila Kawin lari merupakan langkah yang sangat fatal dan melanggar aturan adat. Dapot yang sudah dibutakan karena cinta membuat dia lupa akan aturan adat yang ada dalam realitas budaya Partuturon. Konflik percintaan yang semakin bergelora dalam dada Dapot membuat dirinya lebih nekad untuk menikahi Laila termasuk harus membawa paksa Laila dari rumah orang tuanya. Dapot tidak lagi menghiraukan kedudukan ibu Laila sebagai Ompung (nenek) dalam realitas budaya Partuturon. Adegan tersebut dapat terlihat pada capture film Harani Adat berikut ini: 


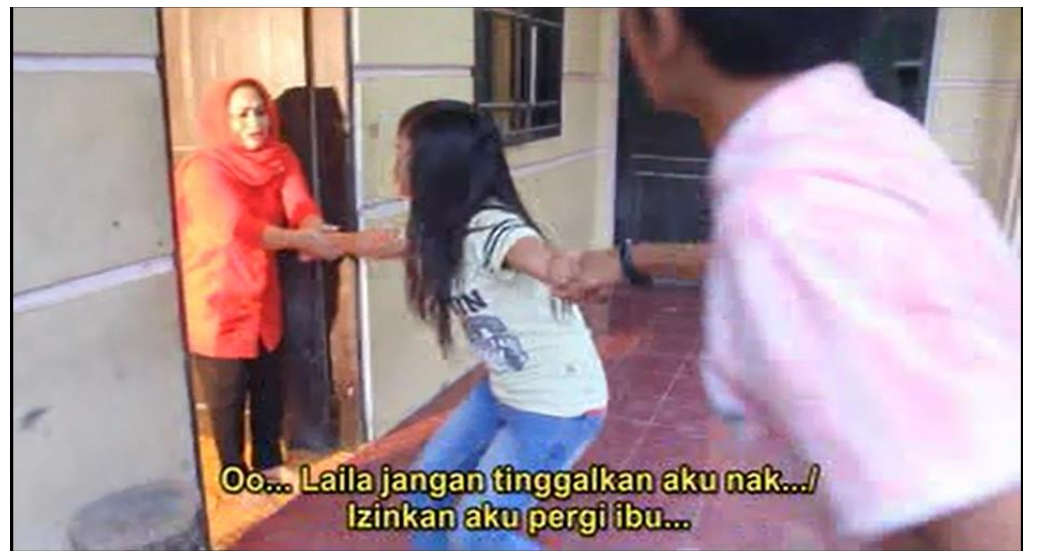

Gambar 7. Dapot tidak menghiraukan Kedudukan Ibu Laila (Sumber : Ali Mursid. Capture film Harani Adat. 2018)

Keinginan Dapot membawa Laila kawin lari tidak berjalan sesuai dengan dugaannya. Hal tersebut disebabkan karena Leman pamannya mengetahui kalau Dapot berusaha membawa Laila kawin lari. Berbagai cara dilakukan pamannya untuk menghalangi keinginan Dapot untuk menikahi Laila yang masih terikat hubungan kekerabatan karena Partuturon. Ketika Leman berusaha mencegah Dapot membawa Laila kabur dari rumahnya membuat Dapot nekat untuk bunuh diri dengan cara terjun ke dalam sungai bersama Laila. Ketika Dapot mengutarakan akan bunuh diri jika tetap dihalangi menikahi Laila membuat Leman sangat marah dan mengatakan lebih baik mereka berdua mati dari pada membawa malu ke dalam keluarga dan merusak aturan yang ada dalam realitas budaya Partuturon. Adapun capture adegan tersebut seperti terlihat pada gambar berikut ini:

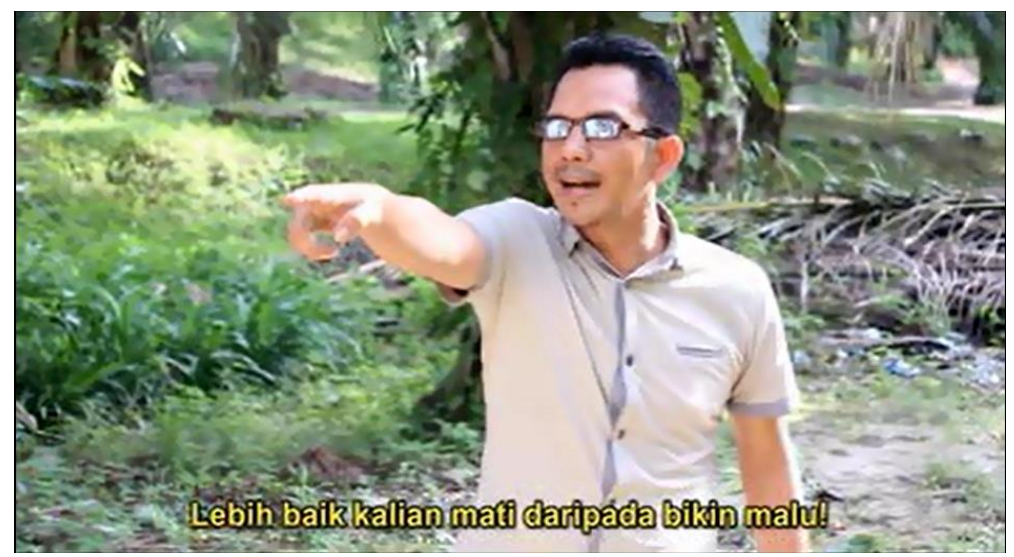

Gambar 8. Leman tidak memperdulikan ancaman Dapot untuk bunuh diri (Sumber : Ali Mursid. Capture film Harani Adat, 2018)

Ketika Dapot mendengar hardikan dari Leman membuat Dapot semakin nekat untuk bunuh diri. Dapot dan Laila melompat ke dalam sungai demi mempertahankan cinta mereka. Merek lebih memilih mati dari pada harus berpisah. Ibarat air yang mengalir dari hulu ke muara tanpa ada rintangan walaupun bebatuan menjadi penghalang air tetap mengalir sampai muara. Adapun adegan Dapot dan Laila terjun ke dalam sungai seperti terlihat pada capture film Harani Adat dibawah ini: 


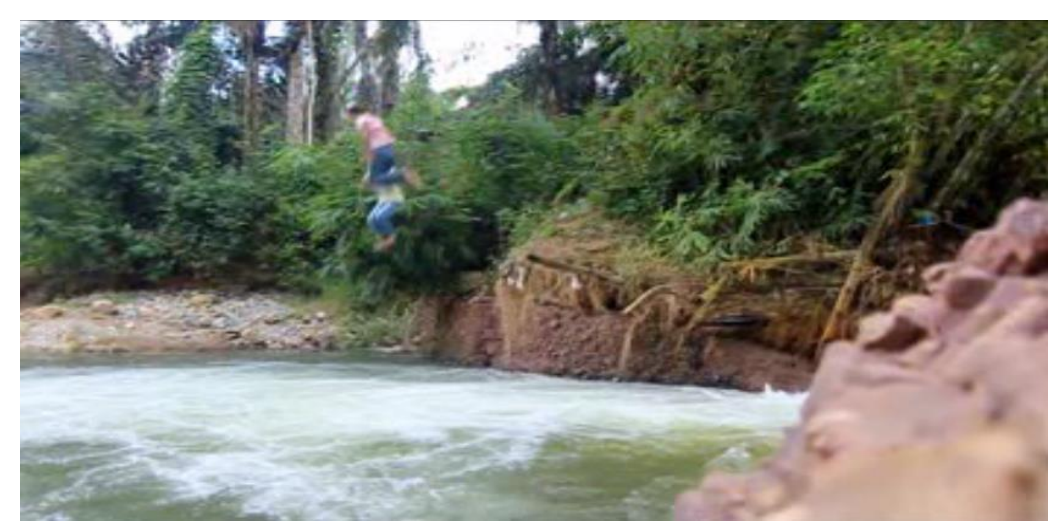

Gambar 9. Dapot dan Laila mencoba untuk bunuh diri (Sumber. Ali Mursid, Capture film Harani Adat, 2018)

Langkah percobaan bunuh diri yang dilakukan Dapot dan Laila tidak membuahkan hasil. Leman dengan penuh wibawa dan tegas dalam menjalankan aturan yang sudah terkonsep dalam realitas budaya Partuturon berusaha untuk mencari Dapot dan Laila di pinggiran sungai. Sebagai seorang paman bagi Dapot sekaligus kakak bagi Laila membuat Leman sangat sedih atas tindakan yang dilakukan mereka. Leman tetap berusaha untuk mencegah Dapot dan Laila menyatu. Leman membawa Laila pulang kerumah orang tuanya dan tidak memperdulikan Dapot yang masih berada di sungai. Dapot yang menyadari keberadaan Laila yang dibawa Leman pulang kerumah orang tua nya membuat Dapot teriak penuh histeris dan berniat untuk membunuh Leman sebagai langkah terakhir agar bisa menikahi Laila. Adapun adegan tersebut terlihat pada scene 27 berikut ini:

26. Ext. Pinggir jalan raya. Pagi

Dapot:

"Gara-gara ni adat mu,sampai hati ho manghina keluarga ku! (gara-gara adatmu, sampai hati kau menghina keluargaku !)"

Leman:

Anak durhako, naso mamboto adat !!!

(Anak durhaka, tidak tahu adat !!!)”. (Sumber. Film Harani Adat. 2018).

Proses perubahan Alur cerita semakin memasuki ranah klimaks. Ketidakberhasilan membunuh Leman dan menikahi Laila membuat Dapot frustasi dan hidup terlunta-lunta di jalanan. Dapot melihat dirinya hidup tanpa arah mencoba untuk menyadari kesalah yang dia lakukan dalam melawan pamanya dan melanggar aturan adat yang tercermin dalam realitas budaya Partuturon. Dapot yang sudah menyadari kekeliruannya berusaha mendatangi kedua orang tua nya untuk meminta maaf begitunya dengan pamannya. Namun, takdir berkehendak lain. Akibat kesalahan yang dia lakukan mengakibatkan dia harus kehilangan orang tuanya. Sepeninggalan orang tuanya Dapot hidup dan tinggal bersama pamannya diperantauan. Dapot membuka lembaran hidup baru dan melupakan Laila yang pernah ia cintai. Suatu ketika Dapot dan Laila bertemu di sebuah masjid. Mereka berdua saling bertegur sapa dan sudah bisa melupakan kenangan yang pernah mereka jalani. Dapot dan Laila sudah bisa menerapkan nilai-nilai yang terkandung dalam konsep realitas budaya Partuturon. Adegan tersebut terlihat pada capture film Harani Adat berikut ini: 


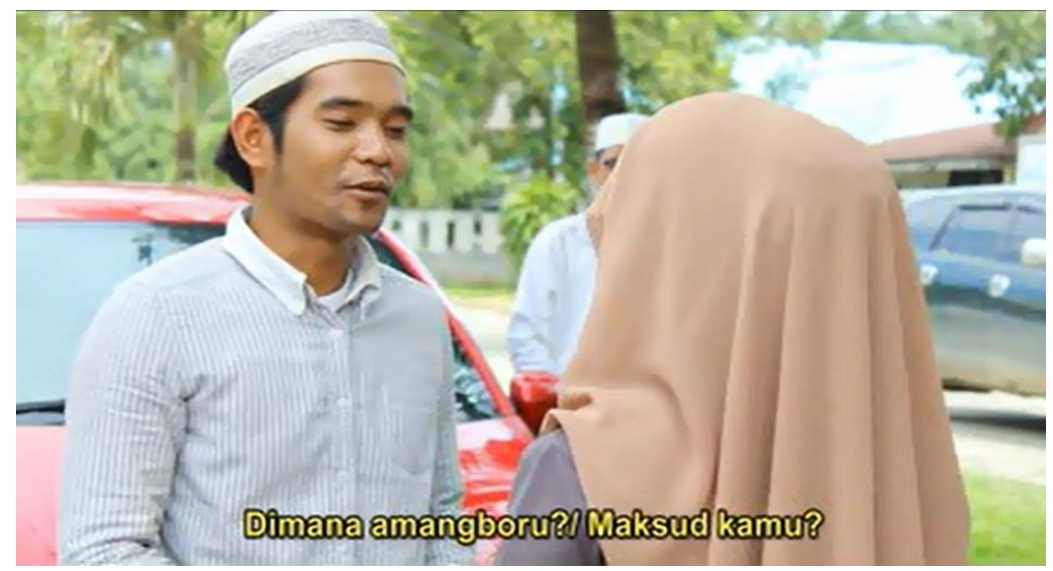

Gambar 10. Dapot dan Laila menerapkan konsep budaya Partuturon (Sumber. Ali Mursid, Capture film Harani Adat, 2018)

Dalam realitas budaya Partuturon terdapat makna tersendiri yang menjurus terhadap larangan Leman yang melarang Dapot dan Laila untuk menikah. Makna tersebut mencerminkan bentuk sosial budaya masyarakat Batak Angkola-Mandailing yang sangat menjunjung tinggi sistem kekerabatan yang sudah terjalin dari nenek moyang mereka. Salah satunya makna hukum adat. Hukum adat adalah merupakan sebuah sistem aturan dalam kehidupan yang berlaku terhadap masyarakat yang ada di dalamnya. Pada umunya, hukum dipahami sebagai seperangkat aturan atau norma, tertulis maupun tidak tertulis yang mengkategorikan suatu perilaku benar atau salah (Saptomo, 2013: 36-37). Hubungan kekerabatan yang terjalin yang disebabkan karena adanya konsep budaya Partuturon merupakan sebauah aturan yang mesti dijalani dan ditaati oleh setiap individu dalam masyarakat Batak Angkola-Mandailing. Selain itu, larangan sebuah pernikahan yang diadaptasi oleh Sulaiman $\mathrm{S}$ selaku sutradara dari realitas sosial budaya juga mencerminkan makna sosial budaya yang berkembang didalam masyarakat Batak Angkola-Mandailing. Makna sosial budaya tercermin dari bentuk interaksi yang senantiasa diterapkan dan dipraktek oleh masyarakat Batak Angkola-Mandailing pada saat berinteraksi sosial dengan sesame

\section{KESIMPULAN}

Proses adaptasi realitas budaya Partuturon yang dilakukan oleh Sulaiman S selaku sutradara. Bertujuan untuk menambah efek dramatik disetiap alur cerita yang terdapat di dalam film Harani Adat. Proses adaptasi realitas budaya Partuturon dalam film Harani Adat diawali dengan proses interaksi antara Torkis dan Martunas. Dalam film Harani Adat juga terjadi proses penambahan yang mengarah ke budaya Partuturon. Proses penambahan bertujuan untuk membuat alur cerita agar memiliki hubungan keterkaitan disetiap adegan. Selain itu, dalam film Harani Adat juga dilakukan proses perubahan dalam alur cerita. Proses perubahan bertujuan agar efek dramatis yang ada dalam film Harani Adat semakin menarik dalam penyampaian bentuk realitas budaya Partuturon yang ada dalam sistem masyarakat Batak Angkola-Mandailing. 


\section{DAFTAR PUSAKA}

\section{Buku:}

[1] Fachruddin, Andi. 2015. Cara Kreatif Memproduksi Program Televisi. Yogyakarta: Andi Offset.

[2] Hutcheon, Linda. 2006. A Theory Of Adaption. New York: Routledge.

[3] Pratista, Himawan. 2008. Memahami Film. Yogyakarta: Homerian Pustaka.

\section{Tulisan/Artikel dalam buku:}

[4] Hadipratama, Bobby. 2017. “Adaptasi Naskah Drama Kocak-Kacik Karya Arifin C. Noer Ke Dalam Pementasan Serta Implikasinya Terhadap Pembelajaran Bahasa Indonesia dan Sastra Indonesia Di SMA (Studi Kasus Pementasan Teater El Na'ma Indonesia)". Skripsi. UIN Syarif Hidayatullah. Jakarta.

[5] Rahmah, Atik Sukriati. 2014. "Analisis Narasi Film 99 Cahaya Di Langit Eropa". Skripsi. Universitas Negeri Syarif Hidayatullah, Jakarta

\section{Jurnal:}

[6] Lubis, Rosliana. 2006. "Partuturon Dalam Masyarakat Angkola". dalam Jurnal Logat. Vol. II, No.1, Medan: Universitas Sumatera Utara.

[7] Pulungan, Husniah Ramadhani. 2015. "Mencegah Terjadinya Pernikahan Sedarah Dengan Memahami Partuturon Dalam Masyarakat Batak AngkolaMandailing". Dalam Jurnal Fitrah, Volume 01, Nomor 2, Padangsidimpuan: Universitas Muhammadiyah Tapanuli Selatan.

[8] Siregar, Rendra Anriadi. 2014. "Penamaan Dan Kesantunan Masyarakat AngkolaMandailing: Tinjauan Antropolinguistik". dalam jurnal Telangkai Bahasa dan Sastra. Tahun ke-8, No. 2, Sumatera Utara: FIB USU.

[9] Saptomo, Ade. 2013. Budaya Hukum dan Kearifan Lokal Sebuah Perspektif Perbandingan. Jakarta: Fakultas Hukum Universitas Pancasila. 